\title{
DETERMINANTES FOR COLLABORATION IN NETWORKED MULTI-USER GAMES
}

\author{
Matthias Rauterberg \\ Technical University Eindhoven (The Netherlands)
}

\begin{abstract}
Game users can behave co-operatively or competitively. An experiment was performed to test the hypothesis that a shared social space (SSS) with continuous and 'rich' communication possibilities leads to an increase in forming coalitions. The DOOM game provides a test environment. Two samples of 12 players each were tested playing DOOM: one with the SSS conditions (continuous communication mode, small physical distance among players) and another under the condition of separation during the game (discontinuous communication mode, large physical distance). During a break all players had have the chance to discuss the outcome of the first trial (group process feedback). The SSS conditions led to a significantly increased amount of coalitions between players. Group process feedback also had a positive effect on the extent of coalitions among players. Finally, design recommendations for networked multi-user games are provided.
\end{abstract}

Key words: Coalition, collaboration, computer game, network, shared social space

\section{INTRODUCTION}

We introduce the concept of 'shared social space' (SSS) for networked computer games. SSS is characterised by the following three different communication aspects: (1) visibility (e.g., facial expression, gesture), (2) audibility (e.g., voice, intonation, sound), and (3) social nearness (e.g., physical distance). The sound aspect can be further differentiated into a verbal and a non-verbal communication channel. Verbal communication can be differentiated into voice (textual information) and intonation (meta-textual information). Non-verbal communication includes (1) information about physical events, (2) information about invisible structures, (3) information about dynamic change, (4) information about abnormal structures, and (5) information about events in space.

The original version of this chapter was revised: The copyright line was incorrect. This has been corrected. The Erratum to this chapter is available at DOI: 10.1007/978-0-387-35660-0_65 
In general, it seems to be difficult to measure co-operative behaviour precisely. Deutsch [1] defines a co-operative social situation such that: the goal-region for each of the individuals in a given situation are defined so that a goal-region can be entered by any given individual only if all the individuals under consideration can also enter their respective goal-regions.

Deutsch [1] defines a competitive social situation as follows. The goals for the individuals in the situation under consideration have the following characteristic: the goal-region for each of the individuals in the situation are defined so that, if a goal-region is entered by any individual, the other individuals will be unable to reach their respective goals. It should be noted that there are probably very few real-life situations where these definitions are 'purely' applicable.

In an empirical study with group sizes between 3 and 6 persons Losada, Sanchez and Noble [2] found the following three relevant results: (1) if collaborative technology was used without feedback of the actual group process, a substantial reduction in socio-emotional interactive sequences was observed; (2) if collaborative technology was used with feedback of the actual group process, a significant increase in socio-emotional interactive sequences was observed; (3) if group process feedback was given without using the collaborative technology, a significant reduction in socio-emotional interactive sequences was observed. The authors suggest, "that group process feedback could be instrumental in reducing social dynamics losses in computer-supported collaborative technology [2]".

One neglected aspect is how to change from competition to co-operation. We assume that a competitive computer game is an appropriate test environment to investigate the change from competitive to co-operative behaviour. We chose the computer game DOOM for our research context.

Following Oberquelle [4] five different levels of demands for the interaction among persons can be distinguished:

(1) informing: anonymous information can be exchanged without knowing each other (e.g., each DOOM player sees the position and the activities of each virtual player without knowing the person behind).

(2) coalition: at least two persons must decide to form a coalition (e.g., two DOOM players decide to play together).

(3) co-ordinating: communication leads to a shared usage of resources; common goals are not necessary; the participants should know each other a little (e.g., DOOM partners exchange the position of the enemy).

(4) collaborating: participants are involved in the same task with different roles; the assessment of each contribution is different (e.g., DOOM partners behave as 'commander' and 'soldier').

(5) co-operating: participants work together to reach a common goal; individual interests and goals are subordinate to the common goal; decisions are carried out together; competition is minimal; participants 
must know each other very well (e.g., DOOM partners have a common strategy to ambush the enemy).

The extent to which SSS influences the readiness to form a coalition rather than only the task solving performance or the amount of socioemotional interactivity in teams (cf. [2]) is unclear.

\section{METHOD}

The DOOM game is appropriate to reconsider the hypothesis that SSS has an influence on the extent to form a coalition. This type of game forces the group members to continually choose between competitive behaviour and to form a coalition. DOOM allows several players to fight against or to play together in the same virtual, highly animated 3D space. If a player meets another player in the virtual 3D room, then he or she has at least three possibilities:

(1) To fight and -- if possible -- to 'kill' the other,

(2) not to fight and -- at least for the actual meeting -- to form a coalition,

(3) to run away or other passive behavior (e.g., not to rise after dying).

The agreement not to attack each other among at least two players can be interpreted as a 'coalition'. A stable coalition can lead to co-operative behaviour over time (e.g., to fight together and to protect each other). A research version of DOOM was implemented such that players could not communicate during the game by keyboard. Therefore, the players needed an additional communication channel to form a coalition. The analysis of the effects of two different kinds of interactions was of primary interest: (1) continuous versus discontinuous communication and (2) group process feedback versus no feedback.

\subsection{GAME ENVIRONMENT}

In a computer training room with eight IBM-PCs connected by Ethernet, two separate clusters of four PCs each were networked. One PC cluster was arranged so that all four players sat in a different corner of the room (large distance condition; see Figure 1). The other PC cluster was in the centre of the room so that each player sat 'side-by-side' or 'back-to-back' with the three other players (small distance condition).

After entering the test room, each player was randomly assigned a coloured badge $(\mathrm{COLOR}=\{$ grey, green, red, yellow $\})$. Each PC screen had a coloured sheet of paper on top of the screen, as well. All colours corresponded with the colours of the virtual bodies inside DOOM. The input device was the keyboard; the output device was a colour screen (IBM 17 inch). 


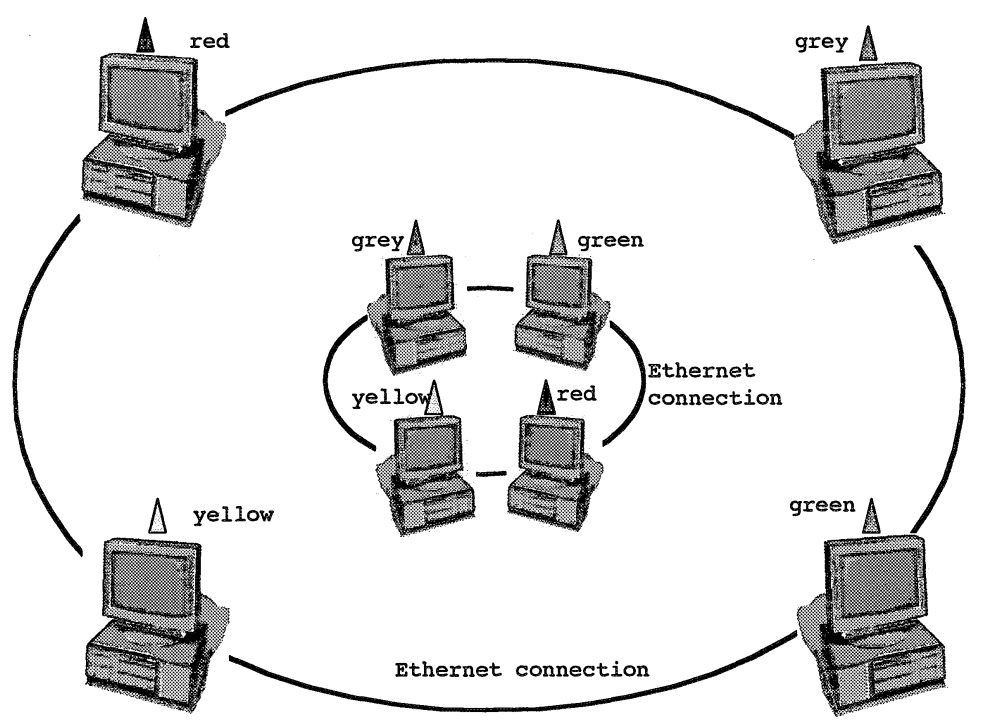

Figure 1. View of the set-up and two test-conditions (close versus far distance); the colours are representing the play positions (red, grey, yellow, and green).

\subsection{PLAYERS AS TEST SUBJECTS}

A total of one female and 23 male persons participated as players. Sixteen persons were students of computer science, and the other eight were public servants, free-lancers or researchers. A group with eight subjects played together at the same time in the test room. The age of $83 \%$ of all subjects was among 21 and 30 years, and the age of the others was among 31 and 40 years. To measure the pre-experiences (EXP) with DOOM and other computer games each subject had to count the total number of hours of playing $\left(\mathrm{EXP}_{\mathrm{DOOM}}=19 \mathrm{hrs} \pm 19 \mathrm{hrs}, \mathrm{EXP}_{\text {other games }}=440 \mathrm{hrs} \pm 1408 \mathrm{hrs}\right)$.

\subsection{PLAYING TEST TASK}

Each player was instructed as follows: «You are together with three other players in a room of an unknown building. In this game a hit is the killing of another player. Try to get as many hits as you can. Coalitions with one of the others could be -- but are not necessarily -- helpful. You are alone with the three other players in the room.» 


\subsection{TEST PROCEDURE AND MEASURES}

In this experiment a 3-factorial test design with the following three independent factors was used.

Factor-A: 'Communication mode' ('continuous' versus 'discontinuous') was considered to be a measure of SSS. Players under the small distance condition could continuously and exclusively communicate with each other. Players under the large distance condition had to wear headphones during the game so that they could only communicate during the break (discontinuous communication mode).

Factor-B: 'Group process feedback' (trial-1 'without feedback' versus trial-2 'with feedback') was a repeated within-subject factor. The whole play time was divided into two trials of 15 minutes each with a break of 10 minutes between them. At the beginning of the break all eight players could look at the group process feedback of their results of trial-1 so that they could take the chance to discuss them during the break. The group process feed-back was a diagram with the number of 'killings' (who 'killed' whom, marked by the four colours). This group process feedback can be interpreted as a 'reward structure' (see [3]).

Factor-C: 'Position' is the physical relation between the players' seats ('side-by-side' versus 'back-to-back', see Figure 1). In the set-up, there were 8 different seats: 4 'side-by-side' places (small distance: 'yellow and red' versus 'grey and green'; large distance: 'yellow and green' versus 'red and grey') and 4 'back-to-back' places (small distance: 'yellow and grey versus 'red and green'; large distance: 'yellow and red' versus 'green and grey'). If the aspect of 'social nearness' has an important contribution to the process of establishing a coalition, then the 'side-by-side' players should have a greater chance to form a coalition than the 'back-to-back' players.

We gathered players with a list on a billboard outside the test room. All 8 players of a group were randomly assigned to one of the 8 positions to control pre-existing relationships among some of the test subjects. On three days in a row three different groups were investigated.

\subsection{DEPENDENT MEASURES}

With individual questionnaires all players after both trials were asked whether (or not) they had have a coalition with one or more other players and if yes, with whom (given by the colour). A coalition was coded as "1" and no coalition as "0". Second, to validate the users' answer in the questionnaire, their real behaviour was measured by the number of killings per trial ('\# of killings'). With this data we calculated a second dependent variable: the 'traitor rate' :=SUM [ 'coalition' ${ }_{\mathrm{c}}^{*}$ '\# of killings' ]; c (ECOLOR. 
If the value of 'coalition' is ' 0 ' (no coalition), then the 'number of killings' of another player can be greater ' 0 ' (no traitor case). But, if the value of 'coalition' is ' 1 ' (coalition) and the 'number of killings' of the ally is greater 0 , then we have a 'traitor'. The 'traitor rate' is a sensible measure of the stability of a declared coalition during a trial. The greater the 'traitor rate' is, the less stable is the coalition.

\section{RESULTS}

The results of a 2-factorial analysis of variances (StatView, version 4.02) with one repeated measurement (Factor-B) are given as follows: Factor-A 'communication' df=1, $F=17.7, p<.001$; Factor-B 'feedback' $\mathrm{df}=1, \mathrm{~F}=16.9$, $\mathrm{p}<.001$; Interaction- $\mathrm{AxB} \mathrm{df}=1, \mathrm{~F}=0.47, \mathrm{p}<.501)$.

The Factor-A 'communication' is significant $(\mathrm{p}<.001)$. Continuous spoken communication with small distance and high social nearness (the SSS condition) leads to an increased readiness to form a coalition.

The Factor-B 'feedback' shows also a significant effect ( $\mathrm{p}<.001)$. After the first trial and the group process feedback an increased amount of coalitions can be observed. Communication in the shared social space during the break had a strong impact on coalitions in the second trial. But, group process feedback and communication during the break did not compensate the effect of continuous communication and social nearness (no significant interaction, $\mathrm{p}<.501$ ).

The stability of a coalition -- measured with the 'traitor rate' -- is not significant among the continuous and the discontinuous communication modes $(\mathrm{p}<.054)$. Based on the definition of 'traitor rate', there is a significant correlation between 'traitor rate' and 'coalition' (Pearson Correlation $\mathrm{R}=.43$, $\mathrm{p}<.002, \mathrm{~N}=48$ ); but no significant correlation between 'traitor rate ' and 'number of killings' $(\mathrm{R}=.24, \mathrm{p}<.10, \mathrm{~N}=48)$.

The results of the group averages of the variable 'coalition' are: Factor-A 'communication mode' $\mathrm{MEAN}_{\text {continuous }}=0.625 \pm 0.495$ [N=24], $\mathrm{MEAN}_{\text {discontinuous }}$ $=0.208 \pm 0.415 \quad[\mathrm{~N}=24]$; Factor-B 'group process feedback' $\mathrm{MEAN}_{\text {without }}$ feedback $=0.167 \pm 0.381[\mathrm{~N}=24], \mathrm{MEAN}_{\text {with feedback }}=0.667 \pm 0.482[\mathrm{~N}=24]$.

The MANOVA results of the variable 'traitor rate' are: Factor-A 'communication' $\mathrm{df}=1, \mathrm{~F}=4.2, \mathrm{p}<.0537$; Factor-B 'feedback' $\mathrm{df}=1, \mathrm{~F}=0.2$, $\mathrm{p}<.695$; Factor-C 'position' $\mathrm{df}=1, \mathrm{~F}=1.9, \mathrm{p}<.180$; Interaction- $\mathrm{AxB} \mathrm{df}=1$, $\mathrm{F}=0.8, \mathrm{p}<.392$; Interaction- $\mathrm{AxC} \mathrm{df}=1, \mathrm{~F}=1.6, \mathrm{p}<.223$; Interaction- $\mathrm{BxC} \mathrm{df}=1$, $\mathrm{F}=1.8, \mathrm{p}<.192$; Interaction- $\mathrm{AxBxC} \mathrm{df}=1, \mathrm{~F}=2.3, \mathrm{p}<.147$.

Players under the SSS condition have a high amount of coalitions, but they tend to change these coalitions during the game. It is important to notice that the effects of the Factor-B 'group process feedback' and Factor-C 'position' are not significant. 
Because the standard deviations of the 'traitor rates' among both conditions of Factor-A 'communication' are quite different (MEAN ${ }_{\text {continuous }}$ $=1.42 \pm 2.87[\mathrm{~N}=24], \mathrm{MEAN}_{\text {discontinuous }}=0.13 \pm 0.45[\mathrm{~N}=24]$ ), this effect was retested with Mann-Whitney $(\mathrm{U}=200.5, \mathrm{p}<.0712)$. We interpret this not significant result as a tendency toward increasing instability of coalitions.

To verify the interpretation that the aspect of 'social nearness' of SSS is the critical factor (not the continuous voice communication aspect alone), the correlation between the 'communication mode' and the 'social nearness' (seating position) was analysed. We can find a significant correlation between the Factor-A 'communication' (continuous versus discontinuous) and the Factor-C 'position' during the first trial $\left(\mathrm{CHI}^{2}=4.8\right.$, $\left.\mathrm{df}=1, \mathrm{p}<.029\right)$. A significant correlation was also found between the Factor-A and the Factor-C during the second trial $\left(\mathrm{CHI}^{2}=11.1, \mathrm{df}=2, \mathrm{p}<.004\right)$.

\section{DISCUSSION}

The following aspects should be discussed in more detail: (1) the representative selection of the test subjects, (2) the generalisation of the results to other co-operative computer games, and (3) consequences for the design of networked multi-user games.

First, caused by the gathering method most of the test subjects are students of computer science. The gender distribution is not typical for the average population, but typical for the computer science department. In this sense the results can be generalised for male dominated populations.

Second, one can argue that the results of this study are only confined to computer games with a competitive structure. The groups are randomly assigned and the investigated time span is short (ca. $30 \mathrm{~min}$ ). The randomisation was necessary to avoid a bias caused by friendships among the subjects. The readiness to form a coalition is a necessary pre-condition for collaboration and co-operation. Coalitions cannot be stable in a competitive context. To stabilise coalitions the context of use must have at least three qualities: (1) a common and shared goal structure, (2) a perceivable interdependency of different goals, and (3) participation as a setting for interaction between unequally powerful persons.

Third, one important consequence for the design of networked multi-user games is to avoid game stations at different locations so that a social space cannot be shared during the game playing. At least, an exclusive communication line among all team players should be provided (see further discussion in [7] and [8]).

To come up with design recommendations for competitive team-based games, we will choose a concrete game for further discussion. 'Racing' games' are an appropriate candidate because they can be played team-based 
and in a competitive manner among teams. Most of the given play stations in entertainment centres are providing space for at least two players. To improve these installations we recommend a clear team based set-up, where the seats next to each other can be exclusively reserved for the two team players (e.g. team-A versus team-B; see figure 2), and a clear separation between the two team stations. Given this redesign with an exclusive communication line among the team members, the roles per team member could vary: e.g. pilot and co-pilot, etc.

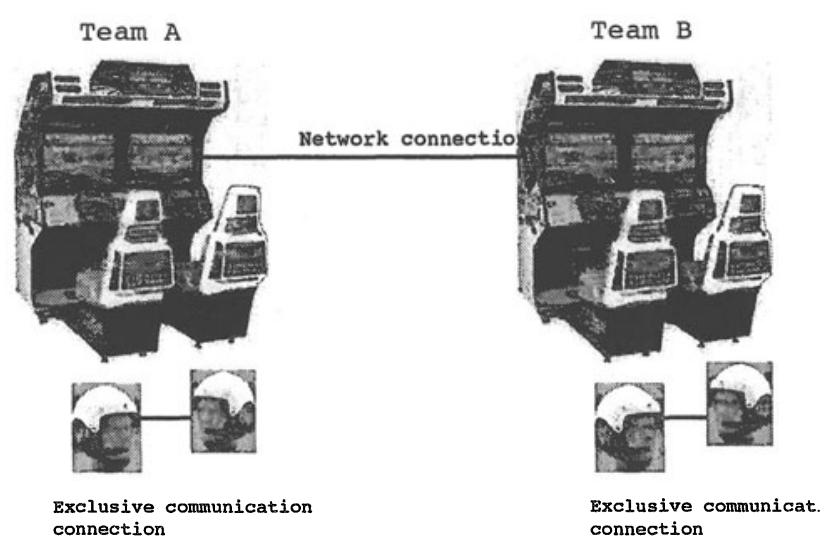

Figure 2. Re-design for racing game installations in entertainment centres.

Finally, we strongly recommend for all competitive games, that the competing players should not be seated next to each other in physical close distance; this often used set-up will probably reduce and limit the amount of the game pleasure.

The following recommendations for the design of team based games with a competitive character can be given:

(1) Feedback about the team results should be provided;

(2) Team players should be seated next to each other to provide an exclusive communication space among all players per team;

(3) Competing players and teams should be seated separately (e.g., in physical distance, or via partition walls);

(4) Feedback about 'traitors' should be an optional feature for all players.

\section{CONCLUSION}

With this investigation, the strong influence of continuous spoken communication -- based on a shared social space -- on the extent and stability of co-operative behaviour was shown. Not only the shared sound space, but also the shared social space and group process feedback (e.g., discussions 
during breaks provoked by the game results) increased the readiness to form a coalition. Due to the competitive character of game the stability of each coalition cannot be stable over time [5]. Social isolation during game playing leads to a low coalition rate and should be avoided in the context of team based game applications with competitive character. At least an exclusive spoken communication channel among all players in a team is one crucial factor for increased game pleasure.

Acknowledgements: I have to thank the following persons for their generous support: M. Sperisen, M. Dätwyler, R. Largo, A. Weiss and C.A. Zehnder at the Computer Science Department of the ETH in Zurich (Switzerland). Finally I would like to thank the three anonymous reviewers for their valuable comments.

\section{REFERENCES}

[1] Deutsch, M. (1949) A theory of co-operation and competition. Human Relations 2: 129-152.

[2] Losada, M., Sanchez, P. \& Noble, E. (1990) Collaborative technology and group process feedback: their impact on interactive sequences in meetings. in Proceedings of the Conference on Computer-Supported Cooperative Work. - CSCW'90. (pp. 53-64), New York: ACM.

[3] McGrenere, J.L. (1996) Design: educational electronic multi-player games -- a literature review [see April 2002: http://www.cs.ubc.ca/labs/imager/th/pdf/mcgrenere.msc.1996.pdf].

[4] Oberquelle, H. (1991) Computergestützte Kommunikation und Kooperation. in H. Oberquelle (Ed.) Kooperative Arbeit und Computerunterstützung. (pp. 1-10), Göttingen: Angewandte Psychologie.

[5] Kaptelinin, V. \& Cole, M. (1997) Individual and collective activities in educational computer game playing. In: Proceedings of Computer Support for Collaborative Learning CSCL'97.

[6] Inkpen, K., Booth, K.S., Gribble, S.D., \& Klawe, M. (1995) Give and Take: Children Collaborating on One Computer. In: Proceedings of CHI '95, Conference Companion. ACM press, 258-259.

[7] Friedland, N. (1990) Attribution of control as a determinant of cooperation in exchange interactions. Journal of Applied Social Psychology v0/4-5 (March): 303-22.

[8] Williams, K. (1997) The Future of On-line Gaming. Interaction Magazine: 7-9. 